Quaestio facti. Revista Internacional sobre Razonamiento Probatorio

Quaestio facti. International Journal on Evidential Legal Reasoning

Vol. 1 | 2020 pp. 271-284

Madrid, 2020

DOI: $10.33115 /$ udg_bib/qf.i0.22372

Marcial Pons Ediciones Jurídicas y Sociales

(C) Olga Fuentes Soriano

ISSN: 2604-6202

Recibido: 06/06/2019 | Aceptado: 15/06/2019

\title{
LA PERSPECTIVA DE GÉNERO EN EL PROCESO PENAL. ¿REFUTACIÓN? DE ALGUNAS CONJETURAS SOSTENIDAS EN EL TRABAJO DE RAMÍREZ ORTIZ «EL TESTIMONIO ÚNICO DE LA VÍCTIMA EN EL PROCESO PENAL DESDE LA PERSPECTIVA DE GÉNERO»
}

\author{
Olga Fuentes Soriano \\ Catedrática de Derecho Procesal \\ Universidad Miguel Hernández \\ ofuentes@umh.es
}

RESUMEN: El presente trabajo pretende, más que refutar -en sentido estricto- las tesis sostenidas en el de Ramírez Ortiz sobre «El testimonio único de la víctima en el proceso desde la perspectiva de género», introducir algunos matices que permitan aportar una visión más amplia del rol que la perspectiva de género está llamada a jugar no ya en el conjunto del proceso penal sino, concretamente, en relación con el testimonio único no corroborado. Partiendo así de la base compartida con el autor de referencia, de que la perspectiva de género no puede colmar situaciones de insuficiencia probatoria - como la que se produciría ante el testimonio único no corroborado- se matizan, sin embargo, muchas otras posibles aportaciones que sí puede incorporar a la valoración de dicho testimonio. De hecho, como se sostendrá, es la perspectiva de género aplicada a la valoración del testimonio único de la víctima y a la corroboración de determinados de sus elementos periféricos, lo que permitirá evitar un importante número de situaciones de testimonio único no corroborado, desmontando interpretaciones asumidas desde la normalidad de unas máximas de experiencia que esconden la perpetuación de las situaciones de desigualdad.

PALABRAS CLAVE: Testimonio único de la víctima; declaración de la víctima; corroboración; presunción de inocencia; perspectiva de género; valoración de la prueba; acervo probatorio. 


\section{GENDER PERSPECTIVE IN THE CRIMINAL PROCEDURE REFUTATION? OF SOME CONJECTURES HELD IN RAMÍREZ ORTIZ'S PAPER «SINGLE VICTIM'S TESTIMONY AND GENDER PERSPECTIVE IN THE CRIMINAL PROCEDURE»}

ABSTRACT: The present paper does not intend to refute -in the strict sense- the theses held in the research work of Ramírez Ortiz, «Single victim's testimony and gender perspective in the criminal procedure». The purpose is to introduce some nuances that explain the role that the gender perspective will play not only in the whole criminal process but, specifically, in relation to the uncorroborated single testimony. I agree with the author of reference that the gender perspective cannot fill situations of evident insufficiency -like the uncorroborated single testimony- but there are many other contributions that can be incorporated into the assessment of this testimony. In fact, as it will be held, the gender perspective applied to the assessment of the victim's testimony and to the corroboration of certain of its peripheral elements, will prevent a large number of uncorroborated single testimonies, which conclude in acquital.

KEYWORDS: Single victim's testimony; victim statement; corroboration; presumption of innocence; gender perspective; evaluation of the evidence; body of evidence.

SUMARIO: 1. Introducción: sobre las conjeturas y su refutación.-2. La perspectiva de género en el proceso; 2.1. El valor hermenéutico de la perspectiva de género.-3. Testimonio único de la víctima y perspectiva de género. 3.1. La víctima como testigo especialmente cualificado. $3.2 \mathrm{La}$ corroboración del testimonio de la víctima.—4. Bibliografía.

\section{INTRODUCCIÓN: SOBRE LAS CONJETURAS Y SU REFUTACIÓN}

Cuando los editores y responsables de la Revista Quaestio Facti se pusieron en contacto conmigo para participar en esta sección que iba a llevar por título (en aquel entonces, todo era un proyecto) «Conjeturas y refutaciones» acepté sin dudar, no tanto porque me halagara que pensaran en mi para aportar algún punto de vista al debate, sino, sobre todo, porque por la trayectoria académica y profesional de sus fundadores tenía el convencimiento de que si lanzaban este proyecto, se convertiría, sin duda en un escenario propicio para el estudio y la reflexión sobre cuestiones jurídicas interesantes y polémicas.

En ese contexto se enmarca el trabajo de Ramirez Ortiz ( El testimonio único de la víctima en el proceso penal desde la perspectiva de género») que se supone que, en las páginas que siguen, deberé refutar.

Si por refutar entendemos «contradecir o impugnar con argumentos o razones lo que otros dicen» ${ }^{1}$, desde este momento advierto al lector que serán escasos los

1 Real academia de la lengua, Diccionario de la lengua española, 23a ed., [versión 23.2 en línea], https://dle.rae.es [Fecha de la consulta: 29/05/2019]. 
puntos en los que "contradiga» o "impugne» las fundadas opiniones que se vierten en el texto de referencia. Así, más que una «refutación»-en sentido estricto- de las tesis sustentadas en el trabajo, trataré de matizar o sugerir la adopción de puntos de vista complementarios o alternativos que, sin rechazar ni, desde luego, impugnar lo sostenido, podrían contribuir a ofrecer una visión omnicomprensiva del tema objeto de estudio y, sobre todo, del contexto en el que se enmarca, que no es otro que la perspectiva de género en el proceso penal.

De manera muy resumida, la tesis de fondo del artículo de referencia pasa por admitir que si bien la perspectiva de género puede ser una herramienta de interpretación útil en concretas fases del proceso penal (especialmente en la fase de investigación), en modo alguno podría utilizarse ésta para tratar de colmar la insuficiencia que pudiera derivar del conjunto de la prueba practicada; y concretamente, la insuficiencia probatoria que deriva de la declaración de la víctima cuándo constituye esta la única prueba de cargo obrante en la causa y carece de corroboración externa.

Pero conviene reparar en el hecho de que, para llegar a esta conclusión, que en su enunciado final comparto, atraviesa el autor por un largo camino procesal en el que la perspectiva de género está llamada a jugar un importante rol interpretativo que, sin embargo, ha pasado inadvertido al tener como único norte el escenario final que genera, a efectos de valoración probatoria, la declaración de la víctima cuando constituye esta la única prueba de cargo.

La clave estará, entre otras muchas cosas, en lo que se entienda por corroborar, la extensión que se dé al término y las exigencias que se precisen para tener por corroborada la narración de la víctima. En este sentido, trataré de poner de manifiesto determinados momentos en los que la valoración de algunos elementos periféricos de los hechos narrados, posible desde la aplicación a éstos de la perspectiva de género, puede llevar a considerarlos como fuentes de prueba corroboradoras de un testimonio que, a partir de ese instante, dejará o bien de ser única prueba de cargo (por cuanto habrán aparecido otras fuentes de prueba de los hechos), o bien dejará de ser un testimonio no corroborado (por cuanto habrán aparecido esos indicios corroboradores del testimonio). Que estemos en uno u otro caso dependerá - tal y como se explicará- del sentido fuerte o débil que se exija de la corroboración. Pero sea como fuera, asentado esto, la conjetura de que la perspectiva de género carecerá de toda relevancia en la valoración del testimonio único no corroborado, deberá, en mi opinión, matizarse.

La refutación que trataré de expresar va a girar en torno a la consideración que se hace en el texto de referencia respecto del testimonio único en su resultado final: testimonio único no corroborado. En primer lugar, porque supone un planteamiento estático de la declaración de la víctima como única prueba de cargo cuando, en realidad, esta no "es», o no "preexiste» al proceso, sino que, antes al contrario, es -eventualmente- el resultado final de la práctica de la prueba y de la valoración de la misma. El testimonio o la declaración de la víctima, igual que el conjunto del acervo probatorio, ha de considerarse desde una perspectiva dinámica cuyo resultado final puede llegar a ser -o no- la existencia de un testimonio único no corroborado. De ser 
así - de resultar, efectivamente, que contamos tan sólo con el testimonio de la víctima no corroborado- la perspectiva de género poco va a poder aportar en su eventual valoración probatoria porque en tal caso, simplemente, éste no se podrá valorar; el autor parte de la base-que comparto- de que el testimonio único no corroborado no tiene valor probatorio.

Pero frente a ello -o junto a ello- cabría matizar que el rol que la perspectiva de género puede desempeñar en la valoración del acervo probatorio no debe quedar circunscrito al exclusivo escenario, final y estático de la existencia, como única prueba de cargo, del testimonio de la víctima no corroborado; sino que debe apreciarse desde una perspectiva dinámica, analizando su influencia y consideración en muy distintos momentos y sobre muy distintas fuentes de prueba. Entre otras cuestiones porque, de lo contrario, el argumento se torna en cierto modo tautológico: 1. El testimonio único no corroborado no se puede valorar, por cuanto resulta insuficiente para desvirtuar la presunción de inocencia que asiste al acusado; 2 . La perspectiva de género no aporta nada en los supuestos de insuficiencia probatoria; 3 . En conclusión, la perspectiva de género no aporta nada en la valoración probatoria del testimonio único no corroborado (lo cual iría de suyo, por cuanto ese testimonio único no corroborado, no se va a poder valorar -ni con perspectiva de género, ni sin perspectiva de género-).

En mi opinión, la clave estará en determinar cuándo cabe entender corroborado un testimonio, qué extremos del mismo se exige corroborar, qué fuentes de prueba pueden ser consideradas como hábiles o suficientes para tenerlo por corroborado y qué rol juega en ese proceso - de corroboración- la perspectiva de género; porque de tener ésta alguna incidencia, ya no será tan clara la afirmación de su irrelevancia en los supuestos de testimonio único no corroborado. Seguirá siendo obvio que la perspectiva de género no puede colmar situaciones de insuficiencia probatoria, pero, quizás, sí pueda contribuir a evitar esas situaciones de insuficiencia probatoria.

A la exposición y desarrollo de las líneas aquí esbozadas dedicaré las páginas que siguen a continuación.

\section{LA PERSPECTIVA DE GÉNERO EN EL PROCESO}

Pese a la brevedad que la forma que debe adoptar esta refutación exige, cualquier estudio sobre la función que la perspectiva de género está llamada a desplegar en el proceso requeriría de una reflexión previa en torno al propio concepto de "perspectiva de género".

Por suerte para esta "refutadora» el impecable tratamiento que de la misma efectúa el artículo de referencia facilitará y agilizará este trabajo al permitir asumir como punto de partida, sus propias consideraciones. 


\subsection{Sobre la perspectiva de género}

Como con acierto plantea RAMírez OrTiz, la perspectiva de género es una herramienta conceptual que, a partir de la conciencia de la situación histórica y presente en que se desenvuelve la mujer, permite aportar criterios válidos para comprender y explicar la sociedad desvelando situaciones que directa o indirectamente legitimen la discriminación y proponiendo nuevas medidas, mecanismos o instituciones que logren y promuevan situaciones y condiciones de igualdad efectiva entre hombres y mujeres.

Así, aplicada al ámbito jurídico «la perspectiva de género puede servir para desvelar aquellas instituciones, reglas y prácticas del derecho que crean, legitiman y perpetúan la discriminación, con el propósito de derogarlas, transformarlas y/o sustituirlas por otras» ${ }^{2}$.

Dado que es en el contexto del proceso en el que se quiere analizar el valor de la perspectiva de género, interesa especialmente la referencia del autor a las prácticas del derecho que crean, legitiman y perpetúan la discriminación. Y ello, porque tales prácticas incluyen, como no podría ser de otro modo, la aplicación de la Ley que realizan nuestros tribunales. Expuesta así la situación y sabido que es, que para aplicar la Ley debe el juzgador, necesariamente, interpretarla, será en ese preciso momento -el de la interpretación- en el que la perspectiva de género deberá jugar un rol fundamental a fin de desterrar prácticas o interpretaciones que perpetúen y legitimen estereotipos de género.

Sin embargo, su cuestionada aplicabilidad desde muy diversas instancias como criterio de interpretación legal requeriría de alguna precisión respecto de su reconocimiento y posición en el ordenamiento.

\subsection{Sobre el valor hermenéutico de la perspectiva de género}

Sostiene la CE en su artículo 9.2 que corresponde a los poderes públicos promover las condiciones para que la libertad y la igualdad del individuo y de los grupos en que se integra sean reales y efectivas; así como remover los obstáculos que impidan o dificulten su plenitud.

Se trata este de un mandato constitucional que informa el ordenamiento jurídico y va dirigido a todos los poderes públicos incluyendo, obviamente, a los jueces en su labor de aplicación e interpretación del derecho. Y no es baladí reparar en el dato de que la interpretación jurídica ha de estar informada por dicho mandato, en tanto en cuanto constituye este la expresión más clara del momento social del Estado que quiere el art. 1.1 CE y que, sin embargo, con tanta frecuencia los jueces tienden a olvidar. La omnipresencia del momento democrático del Estado y la consideración, siempre latente en nuestros Tribunales, de las garantías jurisdiccionales que lo con-

\footnotetext{
2 RamireZ ORTIZ, J.L., 2019: 3.
} 
vierten en Estado de Derecho, relegan a un último plano judicial la obligación constitucional que pesa sobre ellos de garantizar también esa expresión social del Estado promoviendo una aplicación igualitaria de la norma y garantizando que el resultado de dicha aplicación no perpetúe, legitime o consienta situaciones de discriminación.

Y, precisamente, en desarrollo de este mandato constitucional, el art. 4 de la Ley $3 / 2007$, de 22 de marzo para la igualdad efectiva de mujeres y hombres eleva la perspectiva de género a la categoría de principio informador del ordenamiento jurídico ${ }^{3}$, al prescribir que «la igualdad de trato y de oportunidades entre mujeres y hombres es un principio informador del ordenamiento jurídico y, como tal, se integrará y observará en la interpretación y aplicación de las normas jurídica».

Nótese que, si bien la vigencia del principio de legalidad vincula al Juez a la aplicación de la norma, lo hace desde los criterios interpretativos que sienta el art. 3 del Código Civil. De entre ellos y por lo que a nosotros en este momento respecta, especial mención merece la referencia como criterio legal de interpretación a la «realidad social» del tiempo en que la norma ha de ser aplicada.

Es la necesidad de atender a la realidad social de nuestros días -como criterio interpretativo del art. 3 CC- que, por mandato constitucional, obligará al Juez a remover cualquier obstáculo que impida o dificulte la consecución de una igualdad real y efectiva en la aplicación de la norma (art. 9.2. CE), lo que convierte la perspectiva de género en un principio informador del ordenamiento que, como tal, los jueces habrán de respetar en su labor de interpretar el derecho para aplicarlo a la solución del caso concreto.

En consecuencia, pues, «juzgar con perspectiva de género equivale -en palabras de García Porres y Subijana Zunzunegui- a implementar en el enjuiciamiento técnicas jurídicas que faciliten la consecución del objetivo de la igualdad efectiva de mujeres y hombres en el uso y disfrute de los derechos y libertades. En concreto, la perspectiva de género aspira a que los parámetros que utiliza el sistema de justicia para interpretar y aplicar la ley no refuercen, a través de una neutralidad axiológica vinculada a la igualdad formal, las relaciones de poder de los hombres sobre las mujeres, consolidando, de esta manera, la discriminación de estas últimas. Lo que postula, en definitiva, es que el sistema de justicia emplee técnicas de diferenciación que, siendo proporcionadas, logren la equiparación final de lo que en el punto inicial es desigual» ${ }^{4}$.

\subsection{Sobre la aplicación de la perspectiva de género en el proceso}

Constatado así, conforme a los párrafos expuestos con anterioridad, el carácter de principio informador del ordenamiento que corresponde otorgar a la perspectiva de género, huelga decir que su relevancia como criterio interpretativo debe dejarse

\footnotetext{
3 Sobre el tema García Porres, I., y Subijana zunzunegui, I., 20 i 8: 2.

4 García Porres, I., y Subijana zunzunegui, I., 20 i 8: 1 y 2.
} 
sentir en cualquier momento del proceso en el que entren en juego consideraciones, en mayor o menor medida estereotipadas, sobre la actuación que, conforme a una distribución de roles preconcebida, cabe esperar de la mujer o del varón.

Así, si bien es cierto que la investigación judicial propia de la fase instructora constituye un ámbito especialmente adecuado en el que la perspectiva de género permite recabar aquellos datos e informaciones útiles y necesarios para el posterior enjuiciamiento de la causa, reducir a este escenario la trascendental misión que la perspectiva de género puede aportar en el proceso arrojaría, en mi opinión, una visión tan parcial como incompleta.

$\mathrm{Y}$ este constituye uno de los puntos en los que me gustaría matizar -que no, estrictamente, «refutar»- la posición de fondo del texto de referencia. Subyace en el mismo la idea de que el momento en el que la perspectiva de género debe desplegar su mayor efectividad es, precisamente, durante la investigación de los hechos. Se sostiene así con meridiana claridad que aunque la perspectiva de género no permita superar la insuficiencia probatoria que deriva del testimonio único no corroborado de la víctima, "puede servir para indicar al investigador la "hoja de ruta" que ha de seguir para orientar la indagación y hacer acopio de material probatorio»" 5 .

Aun compartiendo - como es el caso- la conclusión final expresada, disiento de la consideración que se desprende del texto y que centra en la investigación el núcleo de eficacia de la perspectiva de género. De nuevo, parece apreciarse en este planteamiento una visión estática del proceso que se explica, además, desde una cierta inversión en los tiempos: el razonamiento parte del testimonio único no corroborado (sin que parezca tener relevancia el hecho de que ésta apreciación tendrá lugar al final del proceso -y que, por tanto, más que como punto de partida debe tomarse como punto de llegada) para constatar que la imposibilidad de ser tenido en consideración no puede suplirse desde la perspectiva de género; a continuación se admite que, ello no obstante, la perspectiva de género sí puede orientar la indagación y el acopio de material probatorio. La reducción del todo, a este esquema de planteamiento obvia razonamientos esenciales en los que conviene reparar.

Si analizamos el orden lógico en el que transcurre el proceso, indudablemente la perspectiva de género puede y debe orientar, desde el primer momento, la actuación indagatoria de la policía judicial y con ella, el acopio de material probatorio. Para ello, resultará fundamental superar los estereotipos de género comúnmente aceptados ${ }^{6}$

5 RamíRez ORTIZ, J. L., 20I9: 33.

6 Comparto con Ramirez Ortiz que «los estereotipos de género, concebidos como grupo estructurado de creencias sobre los atributos personales de hombres y mujeres, implican una variedad de aspectos tales como las características de la personalidad, comportamientos y roles, características físicas y apariencias u ocupaciones y presunciones sobre la vida y orientación sexual. Como construcciones ideológicas y culturales reflejan la estructura desigual de poder existente en la relación entre sexos y pueden desempeñar una función no solo descriptiva sino también prescriptiva en tanto implícitamente, imponen a las mujeres que se adecuen a los roles que se les asignan». RAMIREZ ORTIZ, J.L., 20 I9: 29. 
y evitar los sesgos cognitivos en los que se asientan ${ }^{7}$. Pero una vez hecho esto, la perspectiva de género no «desaparece» para volver a «aparecer» en el momento de analizar si puede colmar o no la eventual insuficiencia probatoria que derive del testimonio único no corroborado $-y$ éste parece ser el escenario que se plantea en el texto de referencia-. La perspectiva de género, como criterio informador del ordenamiento no sólo debe inspirar la labor de investigación y acopio del material probatorio, sino que debe presidir la interpretación y la valoración que haya de realizar el juzgador de todas y cada una de las pruebas practicadas. Y esa valoración no lo es sólo de la prueba directa que obre en la causa (declaración de la víctima, de los testigos, informes periciales, partes médicos, psicológicos...), sino que debe aplicarse también a la prueba indirecta o indiciaria que, en su caso, será la que sirva para corroborar el testimonio de la víctima.

De conformidad con ello, la perspectiva de género constituirá una clave fundamental de valoración, tanto de la declaración de la víctima, cuanto de los diversos indicios o fuentes de pruebas periféricas y colaterales que sin hacer prueba directa de los hechos acaecidos permiten otorgar «credibilidad»-en terminología común de la jurisprudencia- o "fiabilidad» - en la terminología escogida como preferente por Ramirez Ortiz- a la declaración que la víctima ofrezca. De ahí que, como se anunció en un principio, la extensión que se otorgue a la idea de corroboración, o las exigencias que se precisen para tener por corroborado el testimonio de la víctima se conviertan en una cuestión fundamental para el buen entendimiento de los matices que pretendo aportar. Y todo ello sin negar que si, como resultado de la valoración probatoria, la declaración de la víctima -entendida por tanto, como punto de llegada- es la única prueba de cargo del proceso y no se encuentra, además, corroborada por ningún extremo o indicio que le otorgue fiabilidad, la perspectiva de género no podrá -efectivamente- colmar la insuficiencia probatoria que de ello derive. Pero estaremos, entonces, ante un testimonio único no corroborado frente al que la perspectiva de género no podrá hacer nada más; sostener sin embargo la irrelevancia de la perspectiva de género frente al mismo, supone centrarse en el momento final del proceso valorativo con claro olvido de todo el juego anterior en el que esta habrá desarrollado una importante función. Y la importancia de este matiz reside en que, lejos de constituir una simple apreciación formal, la asunción por los jueces de esta aplicación continuada de la perspectiva de género durante todo el proceso (especialmente en la fase de valoración del acervo probatorio) y no ceñida a un estricto y último instante procesal, redundaría previsiblemente, en una disminución muy sustancial -como se tratará de argumentar a continuación- de la cantidad de testimonios únicos no corroborados y con ella, de la cifra de impunidad que arrojan estos procedimientos.

Sobre los sesgos de información y su diferencia de enfoque respecto de los heurísticos, así como sobre el papel de las emociones en el enjuiciamiento, véase NIEVA FENOLL, J., 2007: 69 a 84. 


\section{TESTIMONIO ÚNICO DE LA VÍCTIMA Y PERSPECTIVA DE GÉNERO}

La frecuencia con la que, desde siempre, los juzgadores han tenido que enfrentarse a la resolución de procesos en los que contaban tan sólo con la versión acusatoria de la víctima frente a la exculpatoria del acusado, ha llevado a una interesante evolución jurisprudencial tras la que, superado - al menos, aparentemente ${ }^{8}$ - el axioma «testis unus, testis nullus» ${ }^{9}$ el Tribunal Supremo sienta los criterios de valoración de dicho testimonio.

Así, tras históricas décadas de absoluciones acomodadas en la más absoluta impunidad de -fundamentalmente, aunque no solo- los delitos de violación (por constituir estos el máximo exponente de tan sólo las dos declaraciones de víctima y acusado en el acervo probatorio de la causa), fueron efectivamente, tres los requisitos que la Jurisprudencia convino en exigir como necesarios para otorgar valor probatorio a la declaración de la víctima cuando constituyera ésta la única prueba de cargo en la causa ${ }^{10}: 1$. Ausencia de incredibilidad subjetiva (en tan compleja como enrevesada terminología jurisprudencial); 2) verosimilitud de su declaración mediante la corroboración de determinados datos periféricos; y 3) persistencia en la incriminación. Y, todo ello, desde la consideración inicial de que si cabía plantearse la necesidad de otorgar valor a la declaración de la víctima lo era atendiendo al hecho de que ésta constituye un testigo con un estatus especial.

A la consideración de ese estatus especial, tan confundido últimamente como criticado, cuanto a la amplitud de la corroboración exigida para otorgar valor probatorio a su declaración, se dedicarán las reflexiones que siguen.

\subsection{La víctima como testigo especialmente cualificado}

Si desde hace décadas nuestra jurisprudencia considera a la víctima como un testigo especialmente cualificado, lo hace argumentando que, efectivamente, está en las

8 Sobre la calificación de «aparente» que he dado a la superación de esta posición me pronunciaré más adelante; baste ahora con dejar anotado que, desde el momento en que se exige la corroboración del testimonio único para que alcance valor probatorio, en realidad, lo que se está descartando es la posibilidad de valorar este cuando constituye única prueba de cargo. Elocuente sobre la necesidad de prestar una especial atención a este testimonio y las condiciones en que debe realizarse, resulta la STS 217/2018.

9 La evolución doctrinal en la valoración probatoria de la declaración del testigo único ha sido certera y extensamente tratada por RAMIREZ ORTIZ en el artículo de referencia.

10 El cambio jurisprudencial que comenzó a dejarse sentir a mediados de los 80 , resultó evidente a principios de los 90 y comenzó una consolidación sin fisuras que llega hasta nuestros días. Ejemplo de esas SSTS iniciales y hoy consolidadas pueden ser las de 28 de octubre de 1992, 2 de junio de 1998, 20 de julio de 1998, 19 de octubre de 1998 o 13 de febrero de 1999, a título de ejemplo. Entre las SSTS más recientes y, en cierta medida polémicas (aunque sostengo que, en el fondo y si se leen con atención -más allá de cuatro titulares de noticias-, poco nuevo aportan a la concepción tradicional, aunque flaco favor hacen a la causa de la igualdad en su vertiente de difusión social) son las SSTS 2003/2018, de 24 de mayo y 2182/2018, de 13 de junio. 
mejores condiciones para conocer con exactitud lo ocurrido; pero, precisamente, por su carácter de víctima y, por tanto, por haber sufrido de manera directa la comisión del hecho delictivo su declaración puede estar revestida de una cierta parcialidad o subjetividad que hace necesario extremar las precauciones para su valoración. De ahí precisamente, la consolidación de la exigencia de los tres requisitos anteriormente comentados. Así se consideró desde el principio y así se fue, posteriormente, consolidando ${ }^{11}$.

En los últimos tiempos, sin embargo, se ha querido presentar ante nosotros un salto, procesalmente poco justificado, que pasa de la consideración de la víctima como testigo con un estatus especial, a su consideración como testigo con un estatus privilegiado; los matices diferenciadores saltan a la vista. Se ha sostenido que esta es la postura de las SSTS 2003/2018, de 24 de mayo y 2182/2018, de 13 de junio ${ }^{12}$ cuando en realidad, quizás una lectura sosegada de las mismas no permita sostener dicha afirmación con rotundidad ${ }^{13}$. En todo caso, si con la admisión de ese estatus privilegiado se está reconociendo a la víctima una posición de privilegio que le permita superar el derecho a la presunción de inocencia del acusado al margen de un proceso probatorio racional y objetivo, flaco favor se brinda con ello al proceso penal y a los Derechos Fundamentales de los ciudadanos con claro olvido, por otro lado, de lo mucho que la perspectiva de género puede aportar al proceso. Comparto, efectivamente, la tesis de que la perspectiva de género no puede interpretarse como un estándar de prueba específico en materia de violencia del hombre sobre la mujer; y que, por tanto, no cabe valorar de forma distinta la suficiencia de un testimonio para fundamentar una condena, por el hecho de que quien lo aporte sea un hombre o una mujer ${ }^{14}$.

El mayor valor que la perspectiva de género puede aportar en la ponderación del testimonio de la víctima es lograr que esta se realice suprimiendo todos aquellos estereotipos discriminatorios que de forma consciente o inconsciente han alcanzado la consideración de máximas de experiencia elevando a tal categoría lo que no son sino

11 Especialmente ilustrativa de esta posición resultaron sentencias como la STS de 16 de febrero de 1998 en la que se reconocía ya valor probatorio a la declaración de la víctima, pero razonando en profundidad los extremos periféricos que quedan corroborados y argumentando el porqué de esa necesaria corroboración; porqué que no puede ser otro distinto al riesgo que supone aceptar esta única prueba de cargo para el derecho constitucional a la presunción de inocencia.

12 Esta es la interpretación de Ramírez ORTIZ, J.L., 2019: 25 y 26

13 De hecho, la propia STS 282/2018 de 13 de junio sostiene literalmente que «ello, sin embargo, no quiere decir que la credibilidad de las víctimas sea distinta del resto de los testigos, en cuanto al valor de su declaración, y otorgar una especie de presunción de veracidad siempre y en cualquier caso, pero sí puede apreciarse por el Tribunal con mayor precisión la forma de narrar el acaecimiento de un hecho, por haberlo vivido en primera persona y ser sujeto pasivo del delito, para lo cual se prestará especial atención en la forma de cómo cuenta la experiencia vivida, sus gestos, y, sobre todo, tener en cuenta si puede existir algún tipo de enemistad en su declaración». En todo caso, manifiesto mi desacuerdo -que evidenciaré más adelante al tratar de la necesaria corroboración de la declaración mediante la apreciación de elementos externos- respecto de la especial atención que quepa prestar a la forma de la narración o a los gestos utilizados.

14 García Porres, I., y Subijana zunzunegui, I., 20 i 8: 6. 
consecuencias históricamente asumidas de un entendimiento de la sociedad basado en una artificial distribución de roles y proponiendo su sustitución por otros que contrarresten la influencia de esa cultura patriarcal ${ }^{15}$.

De la importancia de este análisis en la ponderación de las fuentes que permiten tener por corroborado el testimonio de la víctima, me ocuparé en las líneas que siguen.

\subsection{La corroboración del testimonio de la víctima}

Cuando la Jurisprudencia exige de forma constante para la valoración del testimonio único, que se encuentre éste corroborado, persigue otorgarle la credibilidad o fiabilidad suficiente como para desvirtuar la presunción de inocencia que asiste al acusado y permitir, en ausencia de otras fuentes de prueba, fundamentar una sentencia condenatoria. Se trata de alcanzar el convencimiento respecto de su fiabilidad ${ }^{16}$, ante la evidencia, pues, de que el núcleo central del relato fáctico (la comisión del hecho delictivo) no va a encontrar fuentes de prueba distintas de esta declaración. Cabrá entender así, y así lo aprecia la Jurisprudencia, que si tal declaración -única prueba directa de cargo- es fiable, constante y -subjetiva y objetivamente- verosímil, es apta para, en su caso, desvirtuar la presunción de inocencia que asiste al acusado.

Y en este contexto resulta trascendental la aportación que la perspectiva de género pueda hacer a este análisis. Un primer factor fundamental será el de contribuir a determinar qué elementos pueden ser considerados hábiles para corroborar el testimonio de la víctima y permitir que alcance valor probatorio. Expone RAMIREZ OrTIZ en el trabajo de referencia, la existencia de dos tendencias interpretativas al respecto ${ }^{17}$ : una exigencia de corroboración en sentido fuerte, referida a "que el propio hecho de la existencia del delito esté apoyado en algún dato añadido a la pura manifestación subjetiva de la víctima» ${ }^{18}$ y una corroboración en sentido débil, referida a «datos que

15 Siguiendo en este punto a García Porres, I., y Subijana zunzunegui, I., 2018: 6 y 7 cabe considerar entre las tenidas por «máximas de experiencia» a desterrar: 1) El empleo de criterios apriorísticos para definir cómo son las mujeres y los hombres conforme a un arquetipo; 2) La expresión como específico factor de valoración de su relato de indicaciones sobre el tipo de comportamiento que cabe predicar de una víctima cuando sufre una victimización violenta y/o sexual o qué tipo de socialización cabe esperar de la misma después de esta traumática experiencia; 3) La plasmación como regla de conducta exigible de cuál debió ser la actuación de la víctima ante los poderes públicos tras sufrir una agresión, blandiendo, sin matices, el argumento de «la tardanza» en presentar la denuncia como dato concluyente de lo inverosímil de lo denunciado; y 4) La valoración de las retractaciones como manifestaciones inequívocas de la mendacidad de la fuente de prueba, desvinculándola de la ambivalencia emocional que padecen estas víctimas

16 Adopto así la terminología escogida por Ramirez OrTiz en el trabajo de referencia (p. 12) para referirse al control sobre credibilidad del testimonio requerido por la jurisprudencia: «Así las cosas, sería preferible, por su mayor precisión, sustituir el ambiguo término "credibilidad" del testigo por el de "fiabilidad" del testimonio".

17 Ramírez ortiz, J.L., 20I9: 16 y ss.

18 Con cita de jurisprudencia apoyada en la STS 544/2016. 
sin ser propiamente el hecho delictivo atañen a algún aspecto fáctico cuya comprobación contribuya a la verosimilitud del testimonio de la víctima» ${ }^{19}$.

En mi opinión $-y$ aquí, de nuevo, la perspectiva de género está llamada a jugar un rol fundamental-, para que la declaración de la víctima alcance credibilidad o fiabilidad es imprescindible entender que la corroboración que exige la jurisprudencia, lo sea respecto de datos periféricos de los hechos delictivos que la víctima haya emitido en su declaración; exigir que la corroboración lo sea respecto del relato fáctico principal o de concretos elementos del tipo supone exigir otras fuentes de prueba del delito; y ello redundaría de facto en la imposibilidad de que el testimonio único de la víctima pudiera alcanzar, en caso alguno, valor probatorio, pues se exigirían siempre otras pruebas corroboradoras de los hechos (no del testimonio de la víctima).

Comparto así la tesis constitucional de que «la corroboración es la confirmación de otra prueba [el testimonio de la víctima, en nuestro caso], que es la que por sí sola no podría servir para la destrucción de la presunción de inocencia, pero que con dicha corroboración adquiere fuerza para fundar la condena» ${ }^{20}$.

El matiz es importante porque desde la tesis que planteo, la existencia de, por ejemplo, partes médicos de lesiones en una acusación por maltrato físico no constituyen -en el sentido que precisa la jurisprudencia y al no referirse a datos periféricos de la misma- un factor que corrobora la declaración de la víctima -aunque, en su caso, también lo fueran-, sino que constituyen, propiamente, una prueba del hecho delictivo. En consonancia, resulta extraordinariamente injustificada (por no decir arbitraria) la frecuente absolución basada en el silencio de la víctima pese a la existencia de partes médicos, periciales psicológicas y testificales (de referencia, o no) obrantes en la causa ${ }^{21}$ por entender que, al no existir prueba directa a la que corroborar -la declaración de la víctima no se da cuando ésta guarda silencio- dicho acervo probatorio no puede ser tomado en consideración ${ }^{22}$.

Asumido que la perspectiva de género no puede colmar una situación de insuficiencia probatoria, aporta poco al avance jurídico centrar el análisis sobre su eficacia en lo que puede aportar ésta al proceso una vez que lo que nos queda del mismo es el testimonio único de la víctima no corroborado -que, de por sí, no puede alcanzar

19 Ramírez ORTIZ, J.L., 20I9: 18.

20 STC 198/2006, de 3 de julio, reiterada en posteriores como 125/2009, de 18 de mayo.

21 Este tema -entre otros- ha sido objeto de un interesante análisis en el «Estudio sobre la aplicación de la Ley Integral contra la violencia de género por las Audiencias Provinciales» realizado por el Grupo de expertos y expertas en Violencia de género del CGPJ, marzo 2016.

22 Véase el caso de la SAP de Alicante 283/2013, en la que la denunciante se acoge a la dispensa del art. 416 de la LECrim y aunque, ante su silencio, obraban en la causa una documental médica, informes periciales relativos a lesiones, informe psicológico de la mujer y testifical de los Agentes de Policía se justificó la absolución en la imposibilidad de valorar esas fuentes de prueba por ausencia de una prueba directa a la que corroborar. En parecido sentido (aunque ceñido a la declaración de los policías que intervinieron en el atestado y que, aunque me parece igualmente válida, puede presentar algunas aristas que requerirían de una más extensa explicación que excede de los límites de este trabajo) SAP de Madrid 948/2013. 
valor probatorio-; aun siendo importante afianzarse en esta posición, más relevante resultaría, en mi opinión, reflexionar en lo que sí puede aportar la perspectiva de género a la valoración de dicho testimonio a fin de entender: primero, cuándo puede tenerse este por corroborado y, segundo, cuándo aun no dándose este, cabe tener los hechos por probados.

Efectivamente, comparto con RAMIREZ OrTIZ que «la perspectiva de género exige que el relato que realiza la mujer que narra haber sido víctima de actos violentos protagonizados por el hombre se evalúe eliminando estereotipos que tratan de universalizar como criterios de racionalidad simples máximas de experiencia machistas»; pero resulta esencial entender, complementariamente, que la perspectiva de género exige igualmente sustituir tales máximas de experiencia machistas, tradicionalmente asumidas, por nuevas máximas de valoración probatoria basadas en exigencias de igualdad real y efectiva en la interpretación, aplicación y resultado de la aplicación de la Ley. Situación a la que solo es posible llegar desde el entendimiento de la perspectiva de género como un principio informador del ordenamiento que actúa de forma continua y constante durante toda la actuación procesal.

Y, precisamente, desde este entendimiento de la perspectiva de género cabe igualmente analizar otros requerimientos exigidos a los elementos corroboradores del testimonio único, como son la necesidad de que se trate de fuentes ajenas o externas a la propia víctima y que tengan carácter objetivo -es decir, que vayan más allá de la impresión subjetiva que en el juez, pueda causar dicha declaración- ${ }^{23}$. La necesidad de que sean elementos externos y ajenos a la declaración de la víctima reside en que, de no ser así, dichos elementos constituirían o formarían parte -necesariamente- de su propia declaración; y, de admitirse tales indicios corroboradores, se estaría aceptando el absurdo de que la declaración de la víctima se corrobora a sí misma.

Para justificar la necesidad del carácter externo de los indicios que corroboren el testimonio de la víctima se utiliza en el texto de referencia, la diferencia entre coherencia (credibilidad interna del relato) y corroboración de la declaración (comprobación del relato mediante datos objetivos verificables), así como la exigencia de ésta última para apreciar su valor probatorio ${ }^{24}$. Esta diferencia, fundamental en el contexto en el que es traída, no debe hacernos obviar el dato, no menor, de que los indicios han de serlo en relación con un testimonio único y para poder valorar éste como -única, por tanto- prueba de cargo. Los elementos -indicios- que corroboren dicha declaración, aunque externos, no deberán recaer sobre el hecho delictivo que se pretende probar y en relación con el cual se carece de otra prueba más allá de dicho testimonio (si este fuera el nivel de exigencia de la corroboración sería imposible hablar de única prueba de cargo), sino sobre elementos periféricos del mismo que

${ }^{23}$ Precisamente en este punto concreto, resultará fundamental la motivación a fin de comprobar el iter lógico que ha llevado al Juez a la conclusión (otorgar valor probatorio a la declaración). A favor de esta posición: STS 544/2016 o ST de 18 de diciembre de 2017; con matices, las SSTS 2003/2018, de 24 de mayo y 2182/2018, de 13 de junio; Ponente Magro Servet.

24 RamíreZ ortiz, J.L., 20I9: 14. 
lo que prueban (lo que corroboran) es, además, la coherencia de dicho testimonio. Nótese que cuando se trata de la valoración probatoria de la declaración de la víctima como única prueba de cargo, la posibilidad de actuar sobre un testimonio incoherente carece de toda relevancia: siendo coherente el testimonio, la corroboración de datos periféricos de carácter objetivo corroborará también la credibilidad interna del relato; sin embargo resulta difícil imaginar la virtualidad práctica de un testimonio único incoherente por mucho que determinados datos periféricos del relato aparezcan externamente corroborados. Así, será esa declaración coherente, corroborada con datos externos (no de la comisión del hecho delictivo, sino de elementos periféricos que otorgan la fiabilidad, verosimilitud o credibilidad del testimonio) la que, en su caso, podrá alcanzar valor probatorio ${ }^{25}$.

Ese y no otro es el rol fundamental que jugará la perspectiva de género en la valoración del testimonio único de la víctima, siendo cierto que, con todo y con ello, si careciera éste de corroboración la perspectiva de género no podría colmar la insuficiencia probatoria que de ello deriva; pero siendo igualmente cierto que, entendido así - con perspectiva de género- el proceso de valoración de la prueba, serán muchos menos los casos de testimonios únicos no corroborados.

\section{BIBLIOGRAFÍA}

Fuentes Soriano, o., 2000: «Valoración de la prueba indiciaria y declaración de la víctima en los delitos sexuales", en Problemas actuales de la administración de justicia en los delitos sexuales, Perú: Edit. Defensoría del Pueblo: 151-249.

García Porres,, I., y Subijana zunzunegui, I., 2018: «El enjuiciamiento penal con perspectiva de género", SEPIN, SP/DOCT/75846 (septiembre): 1-13.

Nieva Fenoll, J., 2007: Enjuiciamiento prima facie. Aproximación al elemento psicológico de las decisiones judiciales, Barcelona: Atelier.

RAMírez ORTIZ, J.L., 2019: «El testimonio único de la víctima en el proceso penal desde la perspectiva de género», en Quaestio facti. Revista internacional sobre razonamiento probatorio (núm. 51): 1-45.

25 Cuestiones de espacio impiden profundizar ahora en estas tesis que, en parte, he abordado en Fuentes Soriano, O., 2000: 151 y ss. 